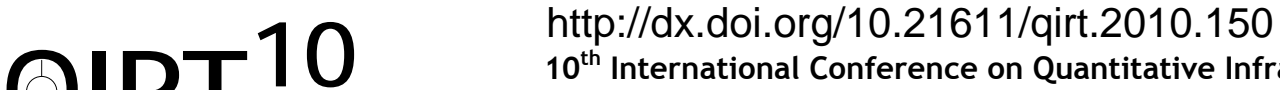 \\ $10^{\text {th }}$ International Conference on Quantitative InfraRed Thermography \\ July 27-30, 2010, Québec (Canada)
}

\section{High resolution and automatic survey of buildings by IR thermography}

\author{
by E. Grinzato*, G. Cadelano*, P. Bison*, F. Peron** and X. Maldague*** \\ *ITC-CNR., Corso Stati Uniti 4, 35127 Padova, Italy, ermanno.grinzato@itc.cnr.it \\ **IUAV university, Venice, Italy \\ ${ }^{\star \star \star E C E ~ D e p t ., ~ U n i v e r s i t e ́ ~ L a v a l, ~ Q u e ́ b e c, ~ C a n a d a ~ G 1 V 0 A 6, ~ m a l d a g u e @ g e l . u l a v a l . c a ~}$
}

\begin{abstract}
The paper illustrates a new approach to achieve the temperature distribution of a buildings composing a global view, at high resolution. It starts from the state of the art and describes how to manage the thermograms content. The on line radiometric calibration of raw thermograms allows obtaining a high accuracy of temperature readings. The calibration is performed using a grid of special targets viewed by the thermographic camera.

An accurate global view of the building envelope is produced with images of thousands per thousands pixels trough an automatic mosaic composition of thermograms. Advanced image processing, including the geometric correction is performed in real time. The final result is a 3D model of the building, georeferenced and with capability to perform heat flux measurements.
\end{abstract}

In addition, IR images, Near IR and visible electromagnetic bands are fused for the building material evaluation.

As case study, the exterior surface of Palazzo Ducale in Venice, is analyzed and illustrated.

\section{Introduction}

Accurate surface temperature measurement of buildings is more and more required for purposes such as energy saving, restoration and comfort evaluation. Infrared thermography has been using since a long time ago in a qualitative way or simply to locate the suitable point, where to install other probing devices. Updated thermographic systems are now ready to fulfill more complex and relevant duties, because of their much higher space and temperature resolution, reduced need of maintenance and lower price. Recent literature shows as thermography used in a quantitative way is an excellent tool for an accurate thermal analysis of indoor and outdoor surfaces [1]. In order to achieve a good cost/benefit ratio some procedures have to be automatized, making results more complete, simple to be interpreted and cost effective, if compared with other methods.

The building surfaces are wide and with different orientations. Therefore, they generally need a composition of many thermograms into a more extended global view. Unfortunately, the radiometric content of thermograms is not preserved if general purposes image processing tools are used. In addition to the need of dedicated software packages, there is also a limited time available. Of course, surface temperature does not change significantly in the order of a few seconds. For this reason, the scanning of the surface has to be fast and precise. This issue is achieved using an automatic device and a special reference grid [2].

For advanced application the accuracy or the temperature measured by thermography must be much higher than that declared in the data sheet. Actually, the temperature map of the surface could vary very little, above all on the interiors. Therefore, a very good accuracy must be reached, of the order of $0.1 \mathrm{~K}$.

A procedure to reach such goals has been set up with a dedicated hardware and software package, that makes faster and simpler the measurement than the standard one.

\section{Materials and methods}

The new Idea is to put in front of the camera a set of special targets, which have manifold purposes. At first, the targets help to reconstruct the correct geometric view of the wall surface. Then, the net of diffusing reflectors allows compensating for the reflected IR radiation coming from the inspected surface. Such a targets set gives also the air temperature in several points. Finally, the automatic scanning device, mounted on a pan-tilt unit, records a set of thermograms and correctly arranges them to form the global view of the surface. In order to increase the accuracy, as generally needed for the most accurate analysis, the system could also be calibrated on a passive reference which provides the air R elative Humidity and the a ir speed component, parallel to the surface [3].

Another feature of the system is to analyze the materials decay, evaluating the thermal effusivity $(e)$ through an energy balance between the solar radiation absorbed by the surface $(Q)$ and the temperature evolution ( $\left.T_{\mathrm{t}}-T_{0}\right)$ in time, described by Equation (1). 


$$
\left(T_{t}-T_{0}\right)=\frac{Q}{h} \sqrt{2} A_{0} \sin (\omega t-\Psi)
$$

where: $h$ is the surface heat exchange coefficient and $\omega$ is the solar angle;

$$
A_{0}=\left(\left(\sqrt{2}+\frac{\sqrt{\omega}}{h} e_{x, y}\right)^{2}+\left(\frac{\sqrt{\omega}}{h} e_{x, y}\right)^{2}\right)^{-1 / 2} \quad \text { and } \quad \Psi=\arctan \left(\frac{\frac{\sqrt{\omega}}{h} e_{x, y}}{\sqrt{2}+\frac{\sqrt{\omega}}{h} e_{x, y}}\right)
$$

Figure 1, shows a result of the procedure as applied on the façade of Palazzo Ducale in Venice for the temperature evaluation. The absorbed energy is also calculated using the global solar radiation measured by a solar radiometer placed on the wall surface and the image given by a calibrated camera working in the visible-Near Infrared (NIR) spectral bands [4].

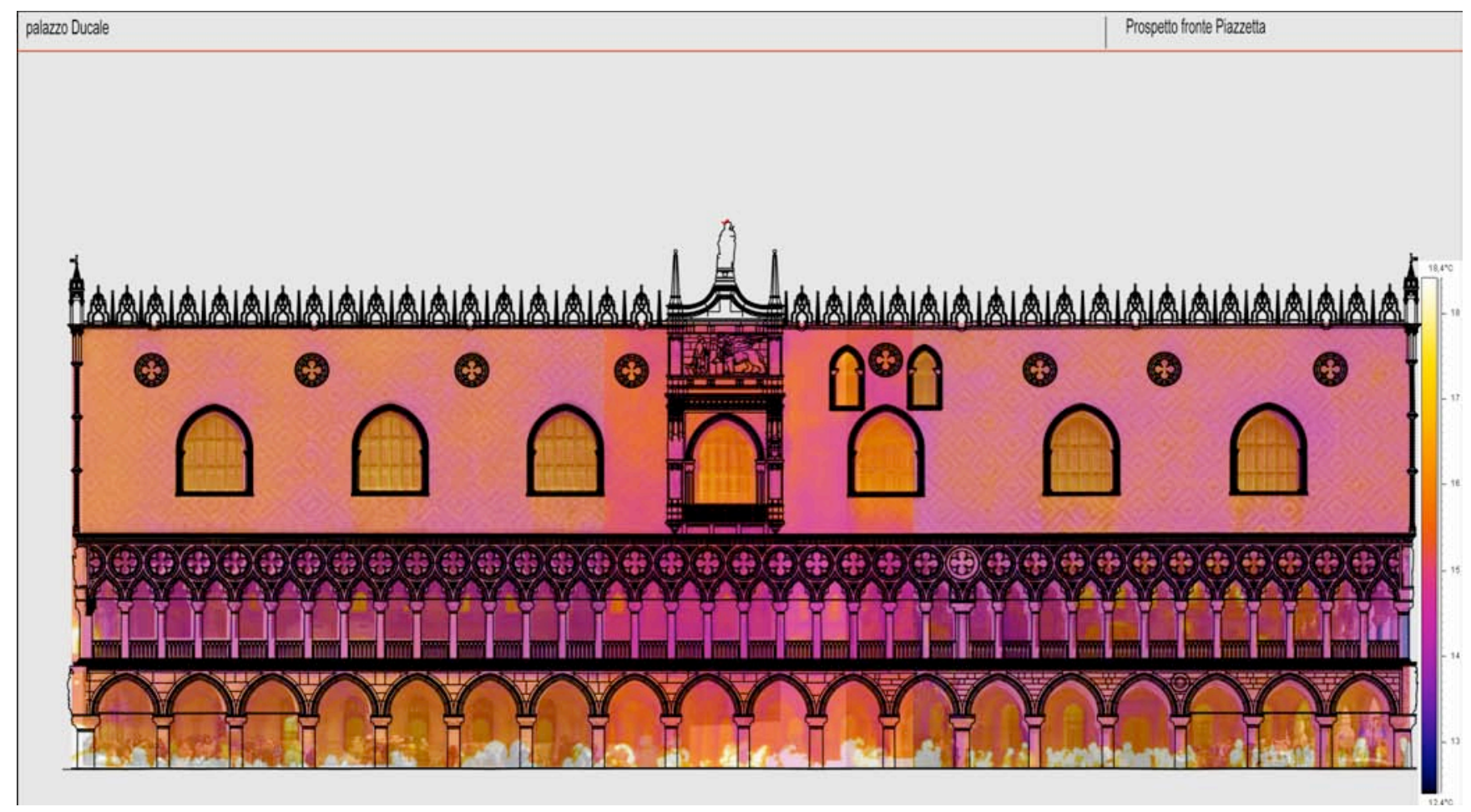

Fig. 1. Surface temperature scanning of Palazzo Ducale in Venice (Italy)

\section{REFERENCES}

[1] Madding R., "Finding R-Values of Stud Frame Constructed Houses with IR Thermography" Inframation ITC 126 A 2008-05-14, Las Vegas, 2008.

[2] Pretto A., Menegatti E., Bison P., Grinzato E., "Automatic Indoor Environmental Conditions Monitoring by IR Thermography". Proceedings of the "6th International Workshop for Advances in Signal Processing for NDE of Materials", in "ASPNDE" 2009 Canada National Conference, 25-27 August 2009, London, Ontario, Canada. In CDROM. (In press on CINDE Journal)

[3] Grinzato E., "A method and apparatus for thermal-hygrometric monitoring of wide surfaces by IR Thermography" patent pending.

[4] Grinzato E., Bison P., Girotto M., Volinia M., "Sull'intonaco e oltre: diagnostica non distruttiva per I monitoraggio del patrimonio storico-monumentale misura in situ dell'effusività termica". Atti del "13 ${ }^{\circ}$ Congresso AIPnd", Roma, 15-17 ottobre 2009, http://www.ndt.net (in Italian). 